\title{
67 \\ The Flight Attendant Who Did Not Smile
}

Flight attendants must always smile. Not an artificial smile, but a genuine one - it must be visible that it comes from within. At the same time, the airlines have constantly been increasing the number of passengers whom flight attendants have to take care of and smile at. Their answer has been to smile less, and when they do smile, it is not always in a genuine way. This resistance gets extra nourishment from a story about a heroine. It goes as follows. A businessman complained to a flight attendant that she did not smile at him. She put down her tray, looked him straight in the eye and said: 'I'll tell you what. You smile first, then I'll smile.' The businessman agreed and smiled. 'Good', she said. 'Now freeze, and hold that for fifteen hours.' And then she picked up her tray and left.

(Hochschild, 2003) 